\title{
Effect of deposition techniques of reinforcement during fabrication of Al-based surface hybrid matrix Metal matrix composite
}

\author{
Kuldip Kumar Sahu, Raj Ballav
}

Research scholar, Dept. of Production and Industrial Engineering, NIT Jamshedpur

Assoc. Prof. ,Dept. of Production and Industrial Engineering, NIT Jamshedpur

\begin{abstract}
Several deposition methods have been proposed for pre-deposition of reinforcement particle for preparation of surface metal matrix composite by Friction Stir Process. The method, which will effectively and homogeneously spread the reinforcement within processed zone, will be considered as best possible method.Homogeneous volumetric metal matrix composites can be fabricated by conventional casting and modified stir casting methods. Friction stir process (FSP) can be used as one of the best technique to fabricate surface modified metal matrix composites. In this research article, silicon carbide and graphite powder are used as reinforced materials and AA6061 is used as parent metal matrix material. FSP which is a versatile surface composite preparation technique is applied for fabrication of surface composite. Herein, single channel, multi-channel and perforated holes methods have been utilized for reinforcement deposition. As per the results, perforated blind holes method is reported as best method of pre deposition of powders. Finally, array of holes for predeposition of reinforcement powder improves approx 25\% in ultimate tensile strength , $40 \%$ in micro-hardness and appreciable grain refinement are observed in metal matrix composite processed by FSP as compared to as received alloy.

Keywords:Friction Stir processing, Graphite, Microstructure, Mechanical properties, Silicon carbide.
\end{abstract}

\section{Introduction}

Whenever designer explore about the light weight, sufficiently strong and good wearable material, Aluminium alloys fits as per the requirements [1]. Al-alloys have specific properties such as high strength to weight ratio, corrosion resistive, easy to be shaped, and abundantly available, which make it a prime material to be used in these industries. However, Al-alloy lacks in terms of wear resistance and surface hardness [2].Wear resistance and hardness can be improved by reinforcing ceramics particles in base Al-alloy and by making it metal matrix composites (MMC) by various methods [3]. Thus, fabricated MMC has improved tribological property, good hardness along with its prime property, i.e., high strength to weight ratio [4]. In various structural parts, the surface layer of components should have high hardness and wear-resistance property along with high toughness[3,4]. For this, surface of the substrate should be reinforced with ceramic phases to enhance tribological performance while the bulk of components retain the original properties as the parent metal. Friction Stir processing(FSP) can be used for the fabrication of surface MMC [5]. Its working principle is similar to that of friction stir welding (FSW). Localized modification and control of microstructures on the near-surface layers of the metallic components can be achieved by FSP while leaves remaining part nearly impassive. During FSP, the near surface layer of the component is subjected to an intense localized heating and due to significant frictional heating and simultaneous stirring of plasticized metal, plastic deformation takes place. This phenomenon replaces the existing microstructure with fine,equi-axes grains. This effect is known as dynamic recrystalisation in the stirred zone [6]. So, properties like tensile strength, ductility, and fatigue strength can be controlled, which are dependent on the grain structure of metal [3,6]. The phenomena of dynamic recrystallization is greatly affected by tool rotation speed, tool traverse rate, vertical pressure exerted on workpiece by tool shoulder, tool geometry, pin profile cooling method etc[7]. Several research work have been reported to prepare surface composites such as $\mathrm{Al} / \mathrm{SiC}$ [7] , $\mathrm{Al}-\mathrm{Mg}-\mathrm{Si} / \mathrm{TiB} 2, \mathrm{Al} / \mathrm{Al} 2 \mathrm{C},[8], \mathrm{Al}-\mathrm{Mg} / \mathrm{TiO} 2$ [9] and $\mathrm{Al} / \mathrm{B} 4 \mathrm{C}$ [10] by FSP. Also, FSP can also be utilized to fabricate intermetallic composites such as Al-Ni and Al$\mathrm{Fe}$ in Al-alloy matrix using metal particles as reinforcement. Hybrid MMC has properties superior to or intermediate to those MMC formed by individual reinforcement in the same metal matrix [11]. FSP provides the freedom to fabricate surface composites of the desired composition, i.e., the desired proportion of matrix and reinforcement particles. out of several work in this field, only few researchers have mentioned the way of reinforcement deposition for preparing samples. The rectangular groove method to pre-deposit reinforcement particles has been reported to fabricate surface MMC [4,6]. Few researchers have also used the number of small blind holes to deposit reinforcement before processing [3-5]. But no comparison between different methods for depositing reinforcement particulate prior to processing has been reported, which might play an important role in the modification of prepared samples of surface MMC. Here, three types of reinforcement deposition methods has been compared which are single channel rectangular groove, parallel multi channel rectangular groove and array of blind holes. The present work is aimed to investigate the suitability of the way of reinforcement powder deposition and the effect of methodology on mechanical and metallurgical properties of fabricated surface MMC. This work has not been submitted previously for publication. 


\section{Experimental Detail}

For Surface metal matrix composites were fabricated by friction stir process. Al-6061 alloy has been used as matrix material. Nano Silicon carbide particles along with graphite powder have been used as reinforcement particle. A modified vertical milling machine has been used for fabrication. Two types of FSP tools, one without pin and another with pin has been used for capping pass and further passes respectively. The detail of process is explained below.

\subsection{FSP tool}

A capping FSP pass has been conducted to avoid loss of reinforcement particles from groove during processing using a flat shoulder FSP tool of shoulder diameter $20 \mathrm{~mm}$ by closing the opening of groove. The FSP was conducted with a rectangular pin of the square cross-section of dimension $5 \mathrm{~mm} \times 5 \mathrm{~mm} \times 4 \mathrm{~mm}$ at a tool rotation rate of $1000 \mathrm{rpm}$ and at traverse speed of $14 \mathrm{~mm} / \mathrm{min}$ along the processing direction. A tilt angle of $2^{\circ}-3^{\circ}$ in the forward direction is provided to the axis of tool with vertical in order to avoid chipping on the surface of stirred zone. The FSP tool was made of a H13 hardened steel [11], and a squire cross-section pin of dimension $5 \mathrm{~mm} \times 5 \mathrm{~mm}$ of depth $4 \mathrm{~mm}$ was used. The chemical composition of tool material is given in table 2 .
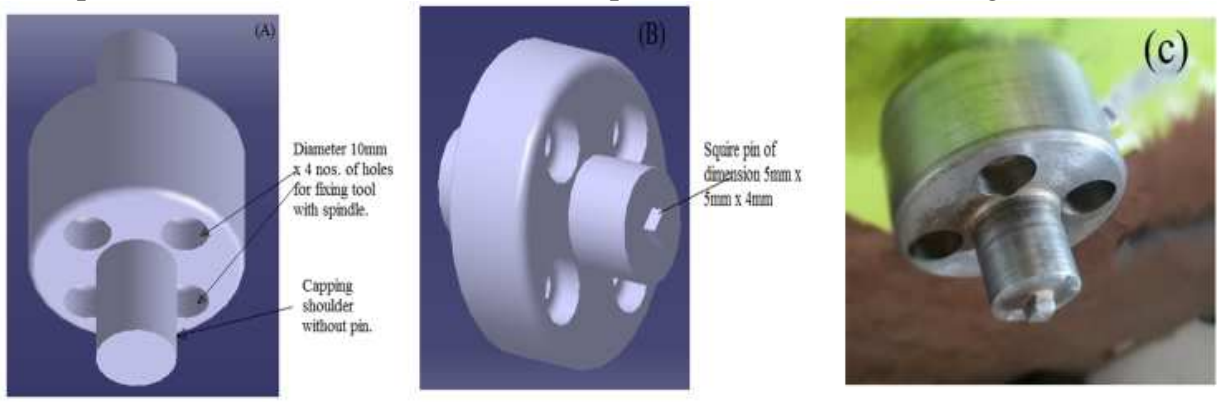

Figure 1 Schematic diagram of tool used for FSP (A) capping tool (b) FSP tool for multipass processing (c) real FSP tool, respectively.

\subsection{Matrix and reinforcement materials}

The metal matrix composites were prepared by using FSP. Total four samples of base metal plate were prepared from a commercially available rolled AA6061-T6 aluminum alloy plate of dimension 100mm x 100mm $\mathrm{x} 5 \mathrm{~mm}$. The nominal chemical composition of the base material is given in Table 1 .

Table 1Chemical composition of base material (AA6061)

\begin{tabular}{|c|c|c|c|c|c|c|c|c|c|}
\hline Component & Al & Mg & Si & Fe & Cu & Zn & Ti & Mn & Cr \\
\hline (Wt \%) & Balance & $0.8-$ & $0.4-$ & Max. & $0.15-$ & Max. & Max. & Max. & $0.04-$ \\
& & 1.2 & 0.8 & 0.7 & 0.40 & 0.25 & 0.15 & 0.15 & 0.35 \\
\hline
\end{tabular}

Table 2 Chemical composition of tool material

\begin{tabular}{|l|l|l|l|l|l|l|l|}
\hline Component & \multicolumn{1}{|c|}{$\mathrm{Fe}$} & $\mathrm{C}$ & $\mathrm{Si}$ & $\mathrm{Mn}$ & $\mathrm{S}$ & $\mathrm{Ph}$ & $\mathrm{Cr}$ \\
\hline Wt. \% & Balanc & $0.95-1.10$ & $\begin{array}{l}.0 .10- \\
0.35\end{array}$ & $0.4-0.7$ & $0.05 \max$ & $0.04 \max$ & $1.2-1.6$ \\
& $\mathrm{e}$ & & & & & \\
\hline
\end{tabular}

\subsection{Methodology}

SiCnano particles with a particle size of 50-100 nm were used as reinforcement ceramic particles along with graphite particles as solid lubricants [11]. For fabrication of the composite samples, the calculated amount of mixture of $\mathrm{SiC}$ and graphite particles in ratio 5:1 were deposited on the middle surface of the base metal specimens in three types of pre-formed grooves. The first type single channel groove (fig.1.A) of groove was in the form of a rectangular groove of size $3 \mathrm{~mm}$ width $4 \mathrm{~mm}$ depth and $100 \mathrm{~mm}$ long along the mid-top surface of Al6061-T6 plat. The second type of groove multichannel groove ( fig. 1.B), in the form of 3 parallel channels of dimension $1 \mathrm{~mm}$ width $\mathrm{x} 4 \mathrm{~mm}$ depth $\mathrm{x} 100 \mathrm{~mm}$ long, was made on the mid surface of the next three plates. On the surface of another three plates, cylindrical blind holes ( fig. 1.C) of $\varphi 2 \mathrm{~mm} \mathrm{x} 4 \mathrm{~mm}$ depth of pitch $4 \mathrm{~mm}$ in 4 parallel rows were made along the midway [14]. 

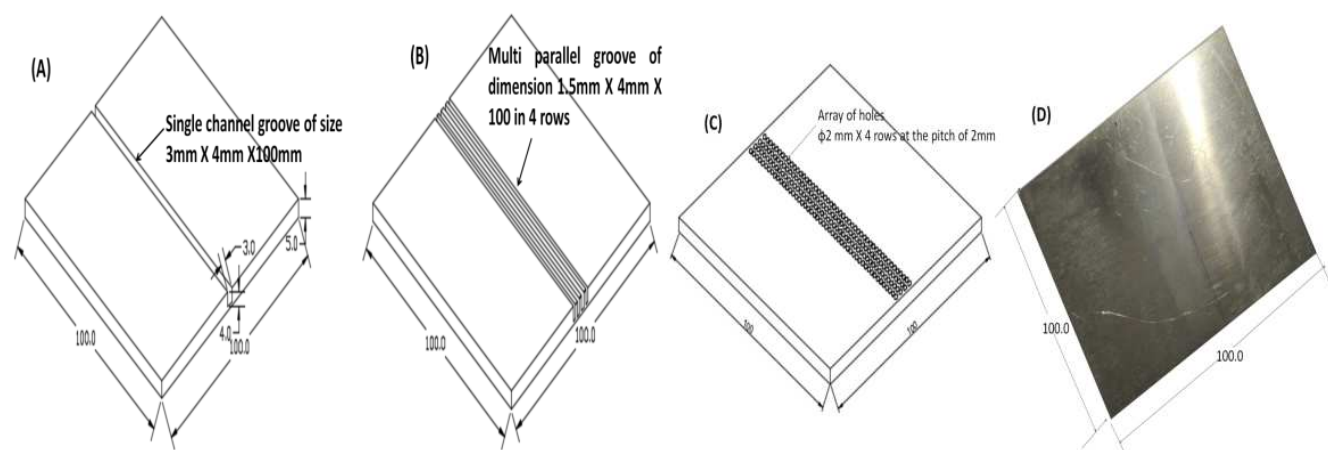

Figure 2 Detail of prepared samples for packing of reinforcement a) single channel groove b) multichannel parallel rectangular groove and c) array of holes d) actual sample.

Prepared composite specimens were subjected to three subsequent overlapping passes with the same rotational direction during FSP to ensure homogeneous distribution of reinforcement particles. All the samples were gone through three FSP pass [15] with a square pin tool at $1000 \mathrm{rpm}$ of rotation at $25 \mathrm{~mm} / \mathrm{minute}$ traverse speed. After capping pass, three overlapping FSP pass has been reported as an optimum number to pass for getting near homogeneous surface metal matrix composite [16]. The set of process parameters has been selected based on the trial experiments and from the result of previously reported works [13-15].

Table 3 Set of process parameters

\begin{tabular}{|c|c|c|c|}
\hline Sample No. & $\begin{array}{c}\text { Method of powder } \\
\text { deposition }\end{array}$ & $\begin{array}{c}\text { Speed of rotation } \\
(\mathbf{R P M})\end{array}$ & $\begin{array}{c}\text { Traverse speed } \\
(\mathbf{m m} / \mathbf{m i n} .)\end{array}$ \\
\hline 01 & FSP without reinforcement & 1000 & 25 \\
\hline 02 & single channel & 1000 & 25 \\
\hline 03 & multi channel & 1000 & 25 \\
\hline 04 & array of holes & 1000 & 25 \\
\hline
\end{tabular}

\subsection{Characterization of the composites materials}

The fabricated samples were collected and prepared accordingly for the different tests Tensile test and microhardness tests samples were cut from the fabricated materials as per test specification. Optical microscopy test, Scanning Electron Microscopy test and EDS tests were conducted on selected samples. The microstructures of the fabricated composite samples were examined using a Zeiss optical microscope. All specimens were initially mechanically polished by 400 to 3000 grit abrasive papers and then cloth polishing was done. Killer's reagent was used as revealing agent for the microstructure of FSPed samples[16].. Tensile testes were carried out at room temperature $\left(25^{\circ} \mathrm{C}\right)$ by using a universal testing machine with electronic recorder at a constant strain rate of $2 \mathrm{~mm} / \mathrm{min}$. The tensile test specimens were prepared as per ASTM standard E8/E8 by using wire cut electric discharge machining to the required dimensions [1]. The specimen dimensions are shown in Fig. 3. A scanning electron microscope was used to reveal the microstructure of prepared samples as well as fractured surfaces obtained from tensile test.

Vicker's Micro hardness measurements were carried out along the cross-section of the nugget region at different points of the processed specimens.

Microhardness measurements were performed by using a Koopa Vickers microhardness tester. Specimen were cut to the required size then polished to get the mirror finish surface. Tensile test samples were prepared as per ASTM E8 standard. A tensile test was conducted on all four samples in universal tensile testing equipment. Applied force and elongation were measured during the testing. Samples were also prepared for optical microscopy test and SEM test. Samples were mechanically polished by sand paper; then cloth polishing was done to achieve mirror-like surface. Samples were treated with killer's reagent to study crystal structure.

\section{Results and discussion}

\subsection{Micro-Hardness test}

The comparative representation of vickermicrohardness of samples is shown in fig.-4. The readings were taken from left to right at $1 \mathrm{~mm}$ interval. The middle layer, i. e. $2 \mathrm{~mm}$ below the top surface, was selected on the cross-section of FSPed sample for the hardness test. The microhardness of as received base metal was uniform 
along the measuring direction, and the average value was recorded as $65 \mathrm{HV}$. The microhardness of FSPed sample without any reinforcement shows a remarkable improvement. The average hardness of stir zone of only FSPed sample was recorded as $76 \mathrm{HV}$ which is $18 \%$ more than that of as-received base metal. This is due to dynamic recrystallization during processing. The microhardness of Thermally Mechanically Affected Zone (TMAZ) have more hardness than the stir zone is observed. This happened due to dynamic recrystallization, pinning effect, and quicker cooling rate than the stir zone. Little improvement in hardness of Heat Affected Zone (HAZ) also noticed due to heating and quick cooling, which is limited to the range of few mm. When silicon carbide ( $\mathrm{SiC}$ ) nano particles were reinforced in base metal along the stir zone by pre-depositing in an array of hole methods, a great improvement in microhardness is observed within stir zone. The microhardness of Al-SiC metal matrix composites within stir zone and along $2 \mathrm{~mm}$ below the top surface was recorded as $94 \mathrm{HV}$, which is $45 \%$ more than that of as-received sample and $26 \%$ more than that of only FSPed sample without any reinforcement for the same zone. The remarkable improvement was due to presence of nano-SiC particles within stir zone as in-situ state. The SiCnano particles also make some intermetallic compound on the boundary of two media which also adds in the improvement of microhardness. The pinning effect in the presence of nanoSiC particles within stir zone plays most important role in improving microhardness. Compared to stir zone, the hardness of TMAZ was always high due to mechanical as well as thermal effect at boundary of static base metal and dynamic stir zone. Quick cooling was the most important reason for increase in hardness. HAZ also shows relative increase in hardness along unaffected base metal to TMAZ according to amount and heating and quick cooling.

Another sample comprising of silicon carbide and graphite nanoparticles mixture as a reinforcement material within the stir zone. This hybrid composite was also fabricated by the same method as depicted in the previous section. Vickers microhardness test of hybrid surface composite reveals that the microhardness value decreases due to the presence of graphite nanoparticles because graphite particles being softer as compared to $\mathrm{SiC}$ particles and base metal [6]. A similar pattern for the hardness of other zones of hybrid composite has been observed as binary composite. Microhardness decreases by $10 \%$ of hybrid composite with compared to that of binary composites within stir zone was recorded.The tensile test was conducted for all four samples. Samples were prepared for the tensile test as per ASTM E8 standard. The tensile test result is shown in fig- 3(A) for all four samples. The tensile test of base metal shows that it has the highest ductility because the received sample was hot rolled with solution age treatment. The FSPed sample without any reinforcement shows little improvement in yield strength but the reduction in percent elongation before fracture. The improvement in tensile strength and reduction in elongation is due to grain refinement during processing. When metal was processed with reinforcement particles, tensile yield strength get improved with a reduction in ductility due to the combined effect of grain refinement and formation of metal matrix composite [17]. The way of deposition of powder affects the distribution of reinforcement powder in the processed zone, thus yield strength. The part of the processes zone will have more yield strength compared to the inhomogeneous region. Therefore, more improvement in strength of processes MMC can be observed in case of an array of holes as a method for packing of powders with respect to single channel and multi channel method. Similarly, hardness test reveals that array of holes method have uniform and high hardness in comparison to other two methods for packing of reinforcement powder along processing zone as seen in fig. 4(B)[2][8].

\subsection{Morphology and microstructure of the composite materials}

Fabricated surface composited samples have been prepared for the study of microstructure and morphology. Cloth polishing and etching of samples have been done before taking microstructure pictures. Fig. 4 represents optical microscopy images of different samples. Fig.4 (A) shows the microscopic image of as-received AL-6061 T6 alloy. 

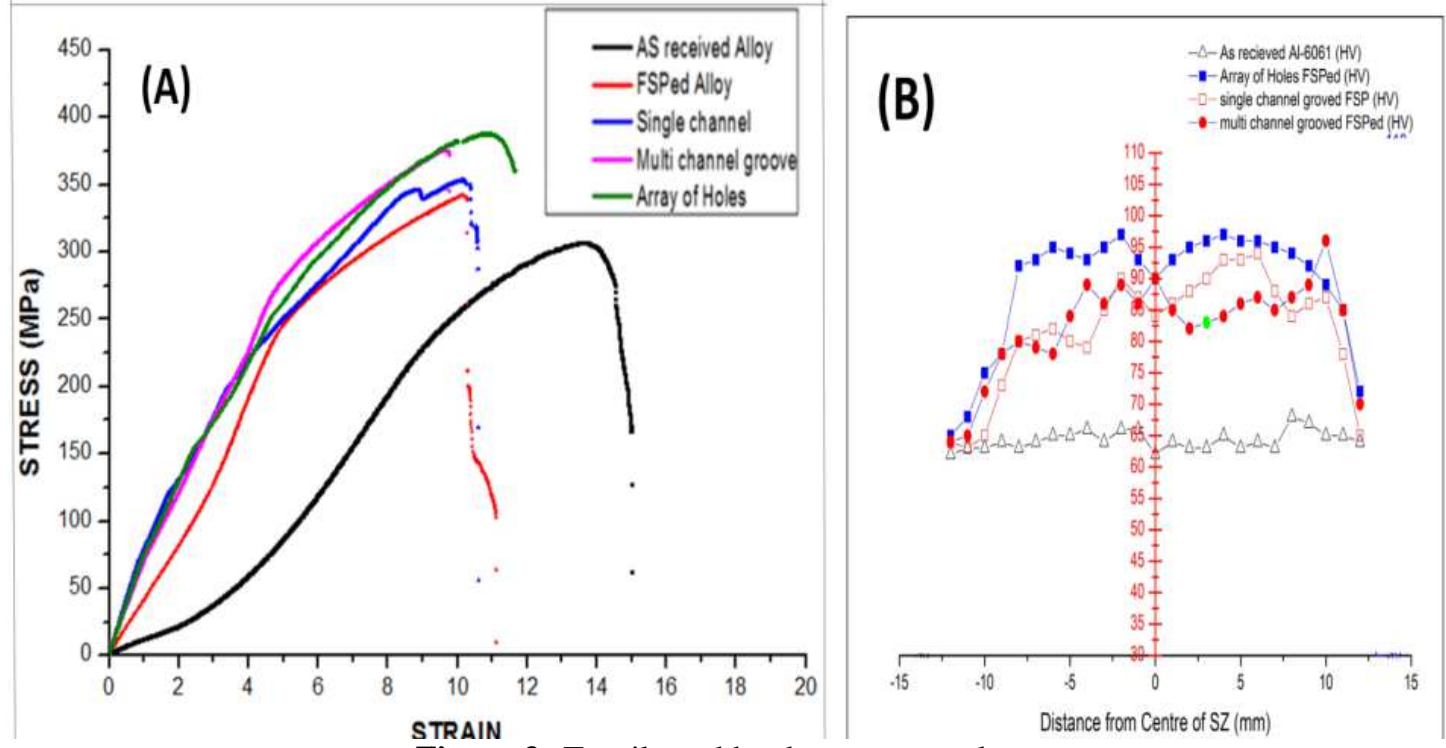

Figure 3 Tensile and hardness test results.

Coarse grain structure can be depicted from the figure. As received, alloy is hot rolled and solution heat-treated. The average grain size is approx 90 micrometers for as received Al-6061-T6 alloy[13][16]. Fig.4(B) shows the optical microscopy images of surface composite fabricated by three consecutive passes of FSP in which reinforcement powder was deposited by single channel groove method, as shown in fig. 1(a). In single channel groove ( $3 \mathrm{~mm} \times 4 \mathrm{~mm} \times 100 \mathrm{~mm}$ ) method, clustering of powder can be observed. In some regions, the uniform distribution of powders can also be viewed. Powder deposition in a single rectangular groove tends to cluster of powders due to depositing the powders along the center of stir zone and even with successive FSP passes, the powders were not properly distributed within the stir zone.
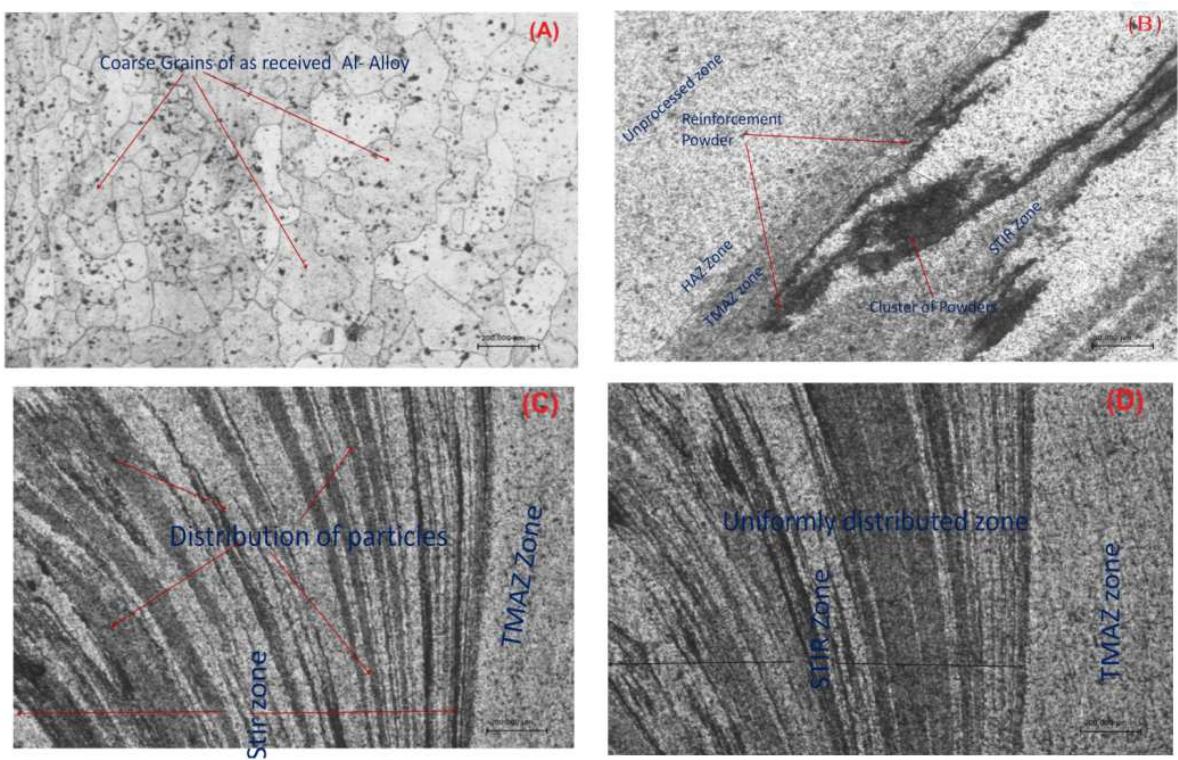

Figure 4 Optical microscopy images of a) As received Al 6061 alloy and surface composites prepared by b) single channel deposition method c) Parallel multi-channel rectangular groove method d) Perforated holes method after 3 passes at 1000rpm rotation speed and $25 \mathrm{~mm} / \mathrm{mint}$ traverse speed.

When the powders were deposited along with parallel rectangular groove (1mm x $4 \mathrm{~mm} \times 100 \mathrm{~mm})$ fig. $1(\mathrm{~b})$, a relatively homogeneous distribution of powders can be observed, as shown in fig.4(C) [18]. 
In the above explained two methods of powder deposition, there is a fundamental problem of escaping of powders from the grove during capping FSP pass and subsequent passes. The powders get displaced in the direction of FSP feed direction due to FSP thrust developed by the plastic flow of material during FSP pass. This results in poor mixing of powder with the matrix material.Fig.4(D) showes the distribution of reinforcement powders within stir zone when powders were deposited in perforated holes in array form along stir zone before FSP. The near-uniform distribution of reinforcement powder can be seen. The reason behind the presence of more particles within stir zone is depositing the powders in blind holes. The blind holes prevent the escaping of powders from the deposited position during capping FSP pass and further passes. Even in the presence of thrust due to plastic flow of material in front of processing, the powders get entrapped in the blind holes, thus eliminates the loss of powders due to escaping. The deposition of powders in perforated holes also provides a packet of the powder in definite intervals during FSP processing.

The deposition of powders in perforated holes also provides a packet of the indefinite powder interval during FSP processing. This uniformly placed packet of powders leads to the uniform distribution of powder within stir zone which can be seen in fig. 5(D).

\subsection{Scanning electron microscopy test}

Samples for scanning electron microscopy were cut from crosss section of all 4 samples after the tensile test. The microstructure was observed using a scanning electron microscope (SEM). Fig. 6(A) reveals the fracture pattern of tensile test. As received, Al-6061 alloy shows that the fracture type is plastic, which can be concluded from observing facture pattern. Fracture patterns in the case of single-channel and multi channel methods of packing reinforcement powder along processing zone are shown in fig. 6 (B) and (C). It seems that the fracture mechanism in these cases is in between ductile and brittle fracture. But in case of an array of holes method( 6(D)), the reinforcement powders have been uniformly distributed along the processed zone; thus, the fracture pattern looks like brittle fracture. The sample has been fractured without neck formation and without significant deformation. The fracture mechanism in fig. 6(D) witnessed that the reinforcement particles have been uniformly distributed along the processed zone.
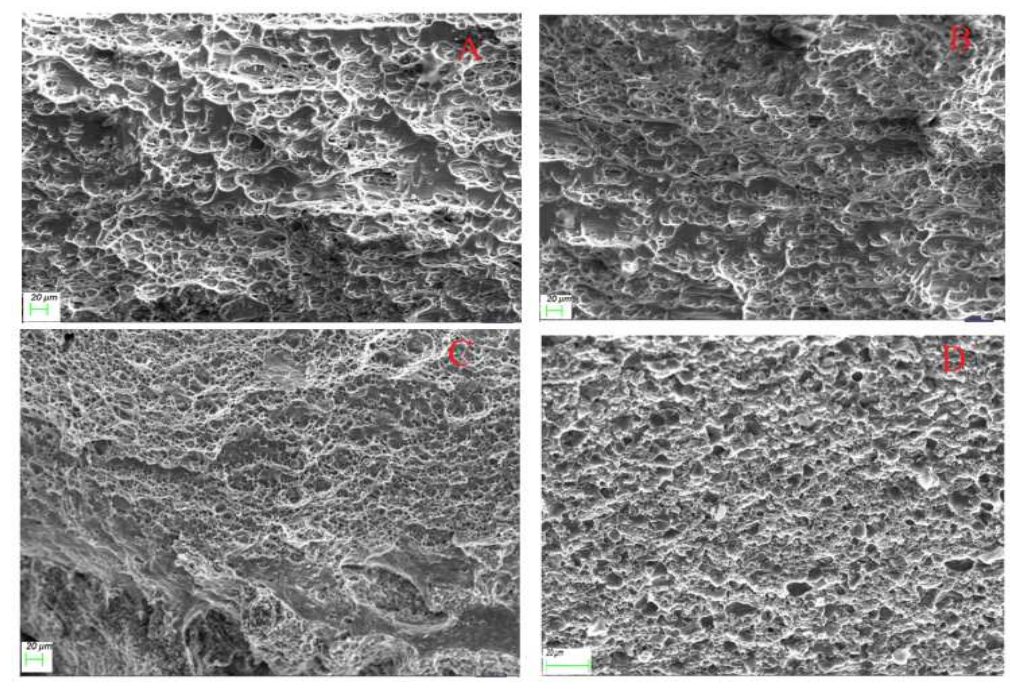

Figure 5 Fracture pattern of a) FSPed alloy b) FSPed MMC fabricated by Single groove method c) FSPed MMC fabricated by multi groove method d) FSPed MMC fabricated by array of holes method. 


\subsection{Energy dispersive X-ray spectroscopy test}

The surface MMC, processed by array of holes method for packing of powder along processing direction, was selected for energy-dispersive X-ray spectroscopy test. The test reveals that, silicon carbide (SiC) particles and graphite particles as solid lubricants were present in the processedzone.Other than these two chemicals, the main constituents such as $\mathrm{Al}, \mathrm{Mg}$ and $\mathrm{Si}$ were also present in all three spots selected for EDS test, as shown in fig.6.

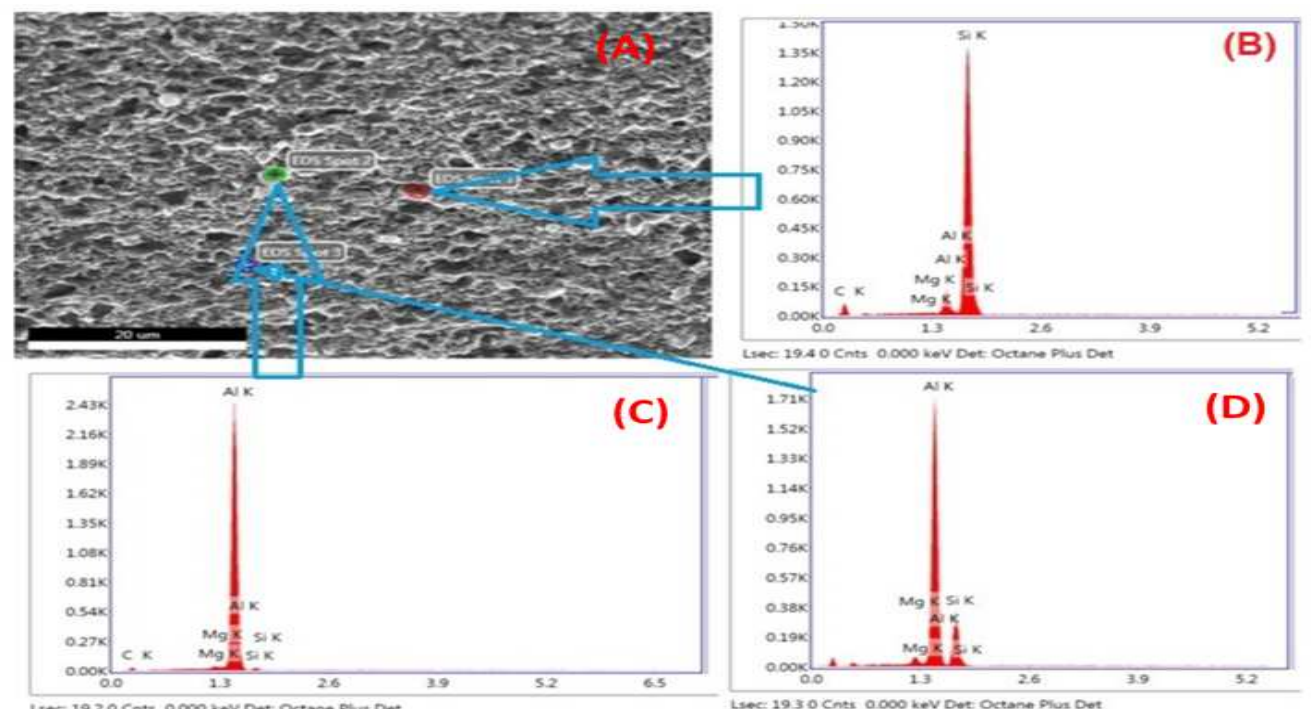

Figure 6 EDS test of sample 4 processed with array of holes method.

\section{Conclusions}

Al-6061/SiC-Grp surface composites were fabricated by different methods of packing reinforcement powders. More homogeneous metal matrix composites were fabricated in an array of hole method as compared to single channel and multi parallel channel method. Hardness was improved in the case of an array of hole methods in a similar way that is in single channel and multi channel method, but uniform hardness was recorded in said case. Higher tensile yield strength was observed in sample-4 i. e. fabricated by array of holes method with respect to the other three samples due to the uniform distribution of reinforcement powder along the processed zone. SEM test reveals that the fracture mechanism in sample-4 (processed by an array of holes method) is a brittle failure, whereas, in other samples, it is a tensile failure. Sample 2 and sample 3 get fractured in lower stress values. EDS result reveals that there is present of all possible elements in the stir zone, thus witnessed the formation of graphite-reinforced hybrid metal matrix composites in the processed zone.

\section{References}

[1] Rahsepar, M. and Jarahimoghadam, H., "The influence of multipass friction stir processing on the corrosion behavior and mechanical properties of zircon-reinforced Al metal matrix composites," Mater. Sci. Eng. A, vol. 671, pp. 214-220, 2016.(Journal)

[2] Singh, S and Pal, K., "Influence of surface morphology and UFG on damping and mechanical properties of composite reinforced with spinel MgAl 2 O 4 -SiC core-shell microcomposites," Mater. Charact., vol. 123, pp. 244-255, 2017.(Journal)

[3] Rudramoorthy, S., et al. "Investigation on structural and Thermal analysis of disc brake with Aluminium Metal Matrix Composite." Int. J. Mech. Prod. Eng. Res. Dev.(IJMPERD) 8 (2018): 431-440.

[4] Dinaharan, I. "Influence of ceramic particulate type on microstructure and tensile strength of aluminum matrix composites produced using friction stir processing," J. Asian Ceram. Soc., vol. 4, no. 2, pp. 209218, 2016.(Journal) 
[5] Soleymani, S.and et al, "Microstructural and tribological properties of ultra fine grained hybrid composite produced by friction stir processing," Mater. Phys. Mech., vol. 17, no. 1, pp. 6-10, 2013.(Journal)

[6] Mohanavel, V., et al. "A review on mechanical and tribological behaviour of aluminium based metal matrix composites." Int. J. Mech. Prod. Eng. Res. Devel. (2018): 473-478.

[7] Kumar, P. Ajay and et al. "A novel in-situ polymer derived nano ceramic MMC by friction stir processing,” Mater. Des., vol. 85, pp. 626-634, 2015.(Journal)

[8] Mohammadzadeh Jamalian, $\mathrm{H}$. and et al, "Processing-structure-property correlation in nano-SiCreinforced friction stir welded aluminum joints," J. Manuf. Process., vol. 21, pp. 180-189, 2016.(Journal)

[9] Rathee, S. and et al "Analysis of Microstructural Changes in Enhancement of Surface Properties in Sheet Forming of Al alloys via Friction Stir Processing," Mater. Today Proc., vol. 4, no. 2, pp. 452-458, 2017.(Journal)

[10] Reddy, A. Chennakesava. "Studies on loading, cracking and clustering of particulates on the strength and stiffness of 7020/SiCp metal matrix composites." International Journal of Metallurgical \& Materials Science and Engineering 5.1 (2015): 53-66.

[11] Azizieh, M. and et al. "Fabrication of Al/Al2Cu in situ nanocomposite via friction stir processing," Trans. Nonferrous Met. Soc. China (English Ed., vol. 27, no. 4, pp. 779-788, 2017.(Journal)

[12] Khodabakhshi, F., Simchi, A., "Surface modifications of an aluminum-magnesium alloy through reactive stir friction processing with titanium oxide nanoparticles for enhanced sliding wear resistance," Surf. Coatings Technol., vol. 309, pp. 114-123, 2017.(Journal)

[13] Rana, H. G.and et al. "Fabrication of Al7075 / B4C Surface Composite by Novel Friction Stir Processing (FSP) and Investigation on Wear Properties," Procedia Technol., vol. 23, pp. 519-528, 2016.(Journal)

[14] Devaraju, A. and et al. "Influence of addition of Grp/A12O3p with SiCp on wear properties of aluminum alloy 6061-T6 hybrid composites via friction stir processing," Trans. Nonferrous Met. Soc. China (English Ed., vol. 23, no. 5, pp. 1275-1280, 2013.(Journal)

[15] Jayavelu, S., et al. "Study on microstructure, mechanical and wear characteristics of sintered AA2014 with alumina and titanium di-boride metal matrix composite." Int J Mech Prod Eng Res Dev 2018 (2018): 125-130.

[16] Kulitskiy, V. and et al. "Grain refinement in an Al-Mg-Sc alloy: Equal channel angular pressing versus friction-stir processing,” Mater. Sci. Eng. A, vol. 674, pp. 480-490, 2016.(Journal)

[17] Khodabakhshi, F.and et al. "Effects of nanometric inclusions on the microstructural characteristics and strengthening of a friction-stir processed aluminum-magnesium alloy," Mater. Sci. Eng. A, vol. 642, pp. 215-229, 2015.(Journal)

[18] Sabbaghian, M.and et al. "Effect of friction stir processing on the microstructure and mechanical properties of Cu-TiC composite,” Ceram. Int., vol. 40, no. 8 PART B, pp. 12969-12976, 2014.(Journal)

[19] Mutar, Mohammed Ail, and Zainab Hamid Abdullah Attab. "Synthesis, Characterization, and Properties of New Unsaturated Polyesters Resins Reinforced with Some Fillers (Carbon Nano, Nano TiO2, TiO2 and $\mathrm{ZnO}$ ) for Composite Application." International Journal of Applied and Natural Sciences (IJANS) 6.3 (2017): 79-100.

[20] Zhao, Y.and et al. "Crystallographic orientations of intermetallic compounds of a multi-pass friction stir processed Al/Mg composite materials,” Mater. Charact., vol. 128, pp. 156-164, 2017.(Journal)

[21] Khorrami, M. Sarkariand et al. "The effect of SiC nanoparticles on the friction stir processing of severely deformed aluminum,” Mater. Sci. Eng. A, vol. 602, pp. 110-118, 2014.(Journal)

[22] Ashjari, M. and et al. "Experimental investigation on the effect of process environment on the mechanical properties of AA5083/A12O3 nanocomposite fabricated via friction stir processing," Mater. Sci. Eng. A, vol. 645, pp. 40-46, 2015.(Journal)

[23] Bauri, R.and et al. "Effect of Process Parameters and Tool Geometry on Fabrication of Ni Particles Reinforced 5083 Al Composite by Friction Stir Processing,” Mater. Today Proc., vol. 2, no. 4-5, pp. 3203-3211, 2015.(Journal) 